\title{
PENGARUH MEDIA ADVERTISING ABOVE THE LINE TERHADAP KEPUTUSAN MENGINAP DI ASTON BRAGA HOTEL AND RESIDENCE BANDUNG
}

(Survei Pada Free Individual Traveller yang Menginap di Aston Braga Hotel And Residence Bandung)

\section{Amalia Juwitasari Gitasiswhara}

\begin{abstract}
As time goes by, the tourism sector in Indonesia has grown and developed into an independent industry sources. National tourism develeopment has the purpose of facilitating the national tourism business, as one source of foreign countries, and the need to improve the organization and functioning of the implementing body in the field of tourism. Hotel industry is an important industry in tourism activities because hotel industry gives a large contribution for tourism sector. Aston Braga Hotel and Residence Bandung as one of four stars hotel in Bandung always strive to maintain aand increase every important aspects which are related to the main goal that is get customer loyalty. The goal can be reached by giving the best services to the guest that greatly exceeds their ecpectations and give an expectional experiences which hard to find in other hotels. In this research, independent variable $(X)$ that used is media advertising above the line which is television, magazine, internet, dan billboard. Dependen variable $(Y)$ is free individual traveller decisison to stay. This type of research is descriptive verification , and the method used sytematic random sampling tehnique, the number of sample obtained for 100 guest who stay Aston Braga Hotel and Residence Bandung. tehniques of data analysis and hypothesis testing used path analysis. The results showed that media advertising above the line significantly influence in decision to stay. The most influential factors for the media advertising above the line is internet which one most higher in reached decision to stay.
\end{abstract}

Keywords: Advertising Above The Line, Guest Decision to Stay

\section{PENDAHULUAN}

\subsection{Latar Belakang}

Perkembangan dunia pariwisata telah mengalami berbagai perubahan baik perubahan pola, bentuk dan sifat kegiatan, serta dorongan orang untuk melakukan perjalanan, cara berpikir, maupun sifat perkembangan itu sendiri. Pariwisata merupakan industri gaya baru yang mampu menyediakan pertumbuhan ekonomi yang cepat dalam hal kesempatan kerja, pendapatan, taraf hidup dan dalam mengaktifan sektor lain di dalam negara penerima wisatawan. Salah satu unsur utamanya dalam pembangunan hospitality industri tersedianya sumber daya yang profesionaldan mampu berkompetensi dalam arena persaingan internasional. Indonesia memiliki daya tarik wisata yang sangat menarik karena memiliki kekayaan alam dan keberagaman budaya sehingga para wisatawan mancanegara (wisman) tertarik untuk datang berkunjung ke Indonesia. Banyaknya Provinsi di Indonesia yang harus dikembangkan agar memiliki potensi wisata yang menarik salah satunya ialah provinsi Jawa Barat sebagai salah satu daerah tujuan wisata di Indonesia, selain Bali, Yogya, dan pulau lainnya yang berada di Indonesia. Oleh karena itu Jawa Barat memiliki produk wisata dan akomodasi yang menunjang sektor pariwisata di Jawa Barat yang dapat terlaksana, sehingga mampu bersaing dalam kompetisi tingkat nasional maupun global. Salah satu kota di Jawa Barat yang meningkatkan sarana akomodasi perhotelan ialah Kota Bandung. Di setiap hotel berbintang empat memiliki ciri khas yang berbeda-beda dimana untuk fasilitas dan harganya salah satunya di Kota Bandung memiliki Aston Braga Hotel and Residence Bandung\& Residence. Aston Braga Hotel and Residence Bandung\& Residence adalah salah satu hotel bintang 4 yang terdapat di kawasan jalan braga dekat wisata gedung Asia Afrika. Berikut room sold atau kamar yang terjualyang di peroleh Aston Braga Hotel and Residence Bandung pada bulan januari dari tahun 2010-2013. 
TABEL 1

ROOM SOLD ASTON BRAGA HOTEL AND RESIDENCE BANDUNG 2010-2013 ROOM SOLD

\begin{tabular}{|c|c|}
\hline \multicolumn{2}{|c|}{ ROOM SOLD } \\
\hline 2010 & $\mathbf{8 2 . 7 5 \%}$ \\
\hline 2011 & $\mathbf{8 4 . 5 8 \%}$ \\
\hline 2012 & $\mathbf{8 1 . 3 0 \%}$ \\
\hline 2013 & $\mathbf{7 1 . 0 0 \%}$ \\
\hline
\end{tabular}

Sumber :Front Office Dept Hotel Aston Braga Hotel and Residence Bandung, 2013

Berdasarkan Tabel 1 kamar yang terjual tahun 2013 mengalami penurunan, kamar yang terjual hanya mendapatkan $71.00 \%$ atau sekitar 47.579 kamar dalam setahun dari 160 kamar. Penjualan kamar ialah salah satu keuntungan untuk hotel yang diperhatikan setiap tahunnya oleh Aston Braga Hotel and Residence Bandung karena merupakan pendapatan hotel. Salah satu media dalam advertising yang dijalankan oleh Aston Braga Hotel and Residence Bandung ialah melalui media advertising above the line (media iklan lini atas) dan media yang digunakan yaitu media TV, radio, surat kabar, majalah, dan papan reklame. Advertising Above The Line merupakan salah satu alat bauran promosi yang memiliki beraneka ragam bentuk dalam pelaksanaannya, yaitu terdiri dari kumpulan insentif-insentif yang berbeda, yang kegiatannya untuk merangsang keputusan menginap yang lebih cepat oleh tamu maka dari itu promosi melalui media advertisingabove the line merupakan salah satu unsur penting dalam kegiatan pemasaran yang bertujuan untuk merangsang tamu dengan cepat untuk membeli suatu produk atau jasa tertentu, dengan demikian perlu diketahui seberapa besar pengaruh kegiatan advertising melalui media advertising above the line yang dilakukan oleh Aston Braga Hotel and Residence Bandung and Residence terhadap tingkat penjualan kamar. Bedasarkan latar belakang tersebut, maka diperlukan suatu penelitian tentang "Pengaruh Media Advertising Above The Line Terhadap Keputusan Menginap di Aston Braga Hotel and Residence Bandung (Survei Pada Tamu Individual Yang Menginap).

\subsection{Rumusan Masalah}

Berdasarkan latar belakang di atas, maka dapat dirumuskan masalah penelitian sebagai berikut :

1. Bagaimana gambaran mengenai media advertising above the line Aston Braga Hotel and Residence Bandung.
2. Bagaimana gambaran tingkat keputusan menginap tamu individual ke Aston Braga Hotel and Residence Bandung.

3. Seberapa besar pengaruh media advertising above the line terhadap tingkat Keputusan Menginap tamu individual di Aston Braga Hotel and Residence Bandung.

\subsection{Tujuan Penelitian}

Berdasarkan rumusan masalah di atas, maka tujuan penelitian ini adalah untuk memperoleh hasil temuan mengenai :

1. Untuk mengetahui gambaran media advertising above the line Aston Braga Hotel and Residence Bandung..

2. Untuk mengetahui Tingkat Keputusan Menginap tamu individual pada Aston Braga Hotel and Residence Bandung.

3. Untuk mengetahui besar pengaruh media advertising above the line terhadap tingkat Keputusan Menginap tamu individual di Aston Braga Hotel and Residence Bandung.

\subsection{Kegunaan Penelitian}

\subsubsection{Kegunaan Teoritis}

Diharapkan dapat memperluas wawasan dan mengembangkan kajian ilmu manajemen pemasaran khususnya mengenai mediaadvertisingabove the line.

\subsubsection{Kegunaan Praktis (empirik)}

Diharapkan dapat memberikan masukan bagi pihak Aston Braga Hotel and Residence Bandungand Residence untuk bahan pertimbangan dimasa yang akan datang oleh perusahaan dalam menentukan media adveritsingabove the line untuk meningkatkan keputusan menginap pada tamunya.

\section{KAJIAN PUSTAKA}

\subsection{Konsep Pemasaran Pariwisata}

Pemasaran merupakan falsafah atau anggapan yang diyakini oleh suatu perusahaan yang berada dalam satu industri untuk memenuhi serta memuaskan keinginan serta kebutuhan konsumen. Pemasaran merupakan suatu konsep yang berorientasi kepada pelanggan melalui pemahaman perilaku secara menyeluruh.

Definisi marketing menurut Kotler dan Amstrong (2012:5) "marketing as the process by which companies create value for customer and build strong customer relationships in order to capture value from customer in return." Artinya "Pemasaran sebagai proses dimana perusahaan menciptakan nilai bagi pelanggan dan 
membangun hubungan yang kuat dengan pelanggan untuk menangkap nilai dari pelanggan sebagai imbalan.”

\subsection{Definisi Above The Line}

Sebuah promosi dapat dikatakan berhasil apabila telah mempengaruhi keberadaan merek dari barang atau jasa dari sebuah perusahaan. Semakin menarik promosi yang dilakukan oleh perusahaan maka konsumen akan menyadari keberadaan produk tersebut, dan akan membuat merek menjadi dikenal oleh konsumen, above the line dan below the line merupakan bagian ari kegiatan promosi. Berikut beberapa pengertian mengenai above the line.

Media above the line merupakan media yang bisa digunakan oleh perusahaan untuk mempromosikan dan memperkenalkan produk kepada pasar. Berikut beberapa penjelasan dimensi media lini atau above the line atas menurut Nelly Nailatie (2008:190)

1. Media Print-Newspaper (Surat Kabar)

2. Media Print-Magazine (Majalah)

3. Media Electronic - Television

4. Media Electronic - Radio

5. E-medias (Internal)

6. POS (Point of Sales) Materials

7. Outdoor Materials

\subsection{Keputusan Menginap}

Tamu pada titik tertentu harus memutuskan antara menginap atau tidak menginap. Menurut Kotler dan Keller (2012:226), dalam melaksanakan niat menginap, tamu dapat membuat lima sub keputusan menginap, yaitu:

1. Pilihan Produk

2. Pilihan Merek

3. Pilihan Penyalur

4. Pemilihan Waktu Pembelian

5. Waktu Menginap

6. Metode Pembayaran

\section{METODE PENELITIAN}

\subsection{Objek Penelitian}

Objek penelitian ini menggunakan jenis penelitian dua variebel bebas (independent variabel) yaitu television $\left(\mathrm{X}_{1.1}\right)$, internet $\left(\mathrm{X}_{1.2}\right), \quad$ magazine $\left(\mathrm{X}_{1.3}\right)$, billboard $\left(\mathrm{X}_{1.4}\right)$. variabel terikat (dependent variabel) yaitu keputusan menginap (Y). Penelitian ini dilaksanakan di suatu kawasan industri pariwisata, yaitu di akomodasi perhotelan Aston Braga Hotel and Residence Bandung. Responden yang dituju dalam free individual traveller yang datang menginap ke Aston Braga Hotel and Residence Bandung.

\subsection{Jenis Penelitian dan Metode Penelitian}

Penelitian ini menggunakan jenis penelitian deskriptif dan verifikatif.dengan metode explanatory survey. Menurut Sugiyono (2012:11) menyatakan bahwa "metode explanatory survey adalah penelitian yang digunakan untuk mendapatkan data dari tempat tertentu yang alamiah (bukan buatan), tetapi peneliti melakukan perlakuan dalam pengumpulan data, misalnya dengan mengedarkan kuesioner, test, wawancara terstruktur dan sebagainya (perlakuan tidak seperti dalam eksperimen)".

\subsection{Populasi, Sampel dan Teknik Sampling}

Populasi pada penelitian ini adalah sebanyak 47.640 orang. Dalam menentukan ukuran sampel $(\mathrm{n})$ dan populasi $(\mathrm{N})$, maka penelitian ini menggunakan rumus sampel Slovin (HuseinUmar, 2008:65) yaitu sebagai berikut :

$\mathrm{n}=\frac{N}{1+N e^{2}}$

Dengan hasil sampel diperoleh sebanyak 100 responden. Dengan menggunakan teknik penarikan sampling yaitu systematic random sampling.

\subsection{Teknik Pengumpulan Data}

Teknik pengumpulan data yang digunakan adalah sebagai berikut:

1. Wawancara

2. Kuesioer

3. Observasi

4. Study Literatur

\subsection{Regresi Linear Sederhana}

Analisis regresi dilakukan bila hubungan dua variabel berupa hubungan kausal atau fungsional. Untuk menetapkan kedua variabel mempunyai hubungan kausal atau tidak, maka harus didasarkan pada teori atau konsep-konsep tentang dua variabel tersebut (Sugiyono, 2008:269). 


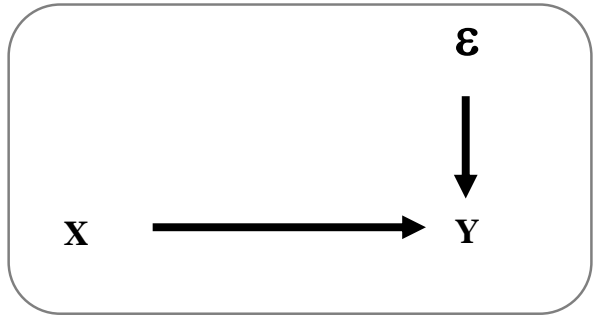

GAMBAR 1

STRUKTUR KAUSAL ANTARA X DAN Y

Keterangan:

$\mathbf{X}=$ Variabel Independen

$\mathbf{Y}=$ Variabel Dipenden

$\boldsymbol{\varepsilon}=$ Epsilon (variabel lain)

\subsection{Hipotesis}

1. Ho: $\mathrm{p}=0$ : Tidak terdapat pengaruh áııı d television $\left(X_{1.1}\right)$ terhadap keputusan Menginap.

Ho: $\mathrm{p} \neq 0$ : Terdapat pengaruh antara television $\left(X_{1.1}\right)$ terhadap Keputusan Menginap.

2. Ho: $\mathrm{p}=0$ : Tidak terdapat pengaruh antara internet $\left(X_{1.2}\right)$ terhadap keputusan mengninap.

Ho: $\mathrm{p}=0$ : Terdapat pengaruh antara internet $\left(X_{1.2}\right)$ terhadap keputusan menginap.

3. Ho: $\mathrm{p}=0$ : Tidak terdapat pengaruh antara magazine $\left(X_{1.3}\right)$ terhadap keputusan menginap.

Ho: $\mathrm{p} \neq 0$ : Terdapat pengaruh antara magazine $\left(X_{1.3}\right)$ terhadap keputusan menginap.

4. Ho: $\mathrm{p}=0$ : Tidak terdapat pengaruh antara bollboard $\left(X_{1.4}\right)$ terhadap keputusan menginap.

5. Ho: $\mathrm{p} \neq 0$ : Terdapat pengaruh antara $\left(X_{1.4}\right)$ billboardterhadap keputusan menginap.

\section{IV . HASIL PENELITIAN DAN PEMBAHASAN}

4.1 Gambaran Mengenai Media Advertising Above The Line

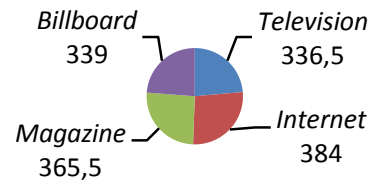

Sumber : Hasil Olah Data,2013

Gambar di atas menunjukan bahwa sub variabel internet memperoleh penilaian tertinggi yaitu dengan skor $384 \mathrm{Hal}$ tersebut membuktikan bahwa media iklan melalui internet memberikan kemudahan bagi responden yang sedang mencari informasi tentang hotel dan juga memudahkan responden untuk memesan melalui reservasi kamar melalui internet. sedangkan yang mendapatkan nilai terendah yaitu achievement dengan skor 336,5 .

\subsection{Gambaran Mengenai Keputusan Menginap}

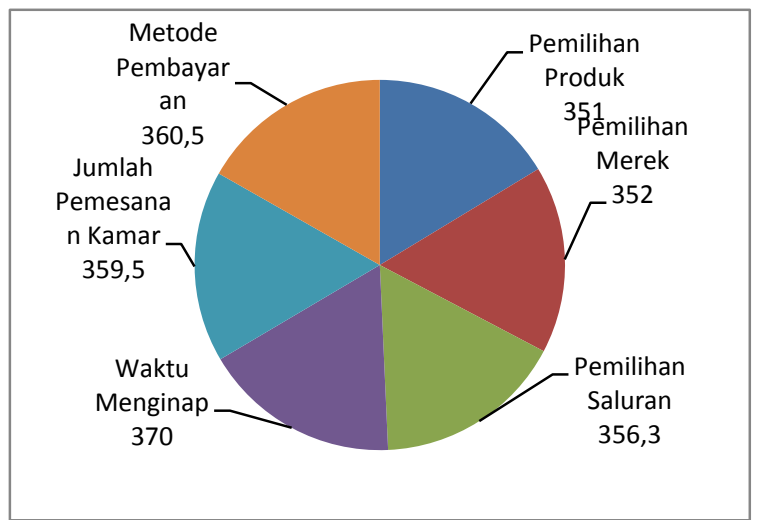

\section{Sumber : Hasil Olah Data,2013}

Berdasarkan gambar di atas menunjukan bahwa penilaian tertinggi dari hasil rekapitulasi tanggapan responden mengenai keputusan menginap yang mendapatkan nilai tertinggi adalah waktu menginap denngan skor sebesar 370 atau $17,21 \%$. Hal ini dikarenakan bahwa pemilihan waktu menginap merupakan faktor utama bagi tamu yang berhubungan dengan pemilhan waktu atau hari untuk menginap.

\subsection{Pengujian Hipotesis dan Uji Signifikansi Secara Simultan (Uji F)}

TABEL 2

UJI KESELURUHAN (ANOVA)

\begin{tabular}{|c|c|c|c|c|c|c|}
\hline \multicolumn{7}{|c|}{ ANOVA $^{a}$} \\
\hline \multicolumn{2}{|r|}{ Model } & \multirow{3}{*}{$\begin{array}{c}\text { Sum of } \\
\text { Squares }\end{array}$} & \multirow{3}{*}{$\begin{array}{r}\mathrm{df} \\
1 \\
\end{array}$} & \multirow{2}{*}{$\begin{array}{c}\text { Mean } \\
\text { Square } \\
2293,93\end{array}$} & \multirow{3}{*}{$\begin{array}{c}\mathrm{F} \\
215,9 \\
91\end{array}$} & \multirow{3}{*}{$\begin{array}{r}\text { Sig. } \\
, 000 \\
\text { b }\end{array}$} \\
\hline \multirow{4}{*}{1} & Regress & & & & & \\
\hline & ion & & & 8 & & \\
\hline & $\begin{array}{c}\text { Residua } \\
1 \\
\end{array}$ & 1040,812 & 98 & 10,621 & & \\
\hline & Total & 3334,750 & 99 & & & \\
\hline \multicolumn{7}{|c|}{ a. Dependent Variable: TOTALY } \\
\hline \multicolumn{7}{|c|}{ b. Predictors: (Constant), TOTALX } \\
\hline
\end{tabular}


Tabel 2 menunjukkan bahwa nilai $\mathrm{F}_{\text {hitung }}=215,991$ dengan tingkat probabilitas sig. 0,000. Data menunjukkan bahwa $F_{\text {tabel }}$ dengan derajat kebebasan sebesar 0,1 yaitu sebesar 2,76, dapat disimpulkan bahwa $F_{\text {hitung }}$ sebesar $215,991 \geq \mathrm{F}_{\text {tabel }}$ sebesar 2,76. dengan nilai signifikansi 0,000 , nilai signifikansi lebih kecil dari taraf signifikansi $0,1 \%$ sehingga jelas $\mathrm{H}_{0}$ ditolak dan Ha diterima.Ha $: \rho \neq 0$, terdapat pengaruh yang signifikan dari advertising above the line yang mempunyai sub variabel yaitu internet, televisi, magazine, dan billboard terhadap keputusan menginap.

\subsection{Pengujian Hipotesis dan Uji Signifikansi Secara Parsial (Uji t)}

Pengujian ini bertujuan untuk melihat pengaruh antara masing-masing variabel independent terhadap variabel dependent, untuk tujuan itu dapat dilihat melalui tabel koefisien regresi berikut ini:

TABEL 3

\section{OUTPUT KOEFISIEN REGRESI}

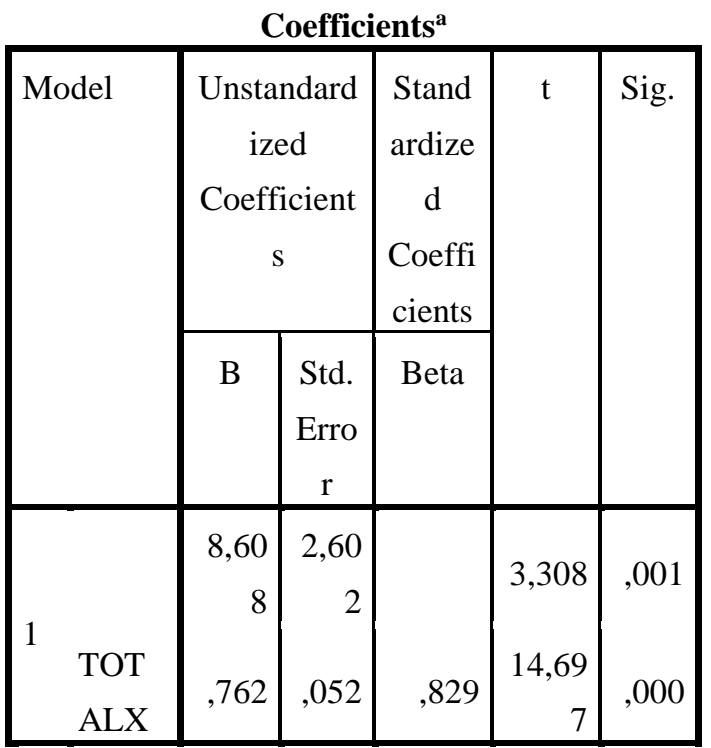

a. Dependent Variable: TOTALY

Sumber: Hasil Pengolahan Data, 2013

Berdasarkan output data di atas, secara parsial semua variabel independent (advertising above the line) mempunyai pengaruh yang signifikan terhadap variabel dependent (keputusan menginap). Hal ini dapat dilihat dari nilai thitung maupun signifikansi nilai signifikansi $(0,000<0,1)$, dimana nilai thitung lebih besar dari $t_{\text {tabel }}$ ( $t_{\text {hitung }}=14,697 \geq 2,62=$ $\left.\mathrm{t}_{\text {tabel }}\right)$, artinya terdapat pengaruh yang signifikan antara program media advertising above the line $(\mathrm{X})$ terhadap keputusan menginap (Y) dengan nilai koefisien regresi 0,762 .

\subsection{Model Persamaan Regresi Linear Sederhana Pengaruh Media Advertising Above The Line Terhadap Keputusan Menginap di Aston Braga Hotel and Residence Bandung}

Hasil analisis data dengan menggunakan program IBM SPSS Statistic versi 2.0 diperoleh persamaan regresi sebagai berikut:

$\mathrm{Y}=\mathrm{a}+\mathrm{bx}$

Berdasarkan hasil pengolahan data maka persamaan regresi untuk analisis program direct marketing adalah:

$Y=8,608+0,762 x$

Keterangan:

$\mathrm{Y}=$ Keputusan menginap

$\mathrm{X}=$ Media advertising above the line

Pada persamaan tersebut nilai B constant adalah 8608, hal tersebut menunjukan bahwa jika advertising above the line diabaikan maka nilai keputusan menggunakan menginap adalah 8608. Apabila media advertising above the line dinaikan sebesar satu satuan maka nilai keputusan menginap akan berubah sebanyak $7,62 \%$.

\section{KESIMPULAN DAN SARAN}

Gambaran mengenai media advertising above the line di Aston Braga Hotel and Residence Bandung yang terdiri dari empat sub variabel yaitu televisi, internet, magazine, billboard. Dari empat sub variabel tersebut didapatkan bahwa yang mendapatkan nilai tertinggi yaitu pada variabel internet, hal tersebut dikarenakan Aston Braga Hotel and Residence Bandung dalam menawarkan produk dan jasanya dalam media internet memiliki informasi yang jelas sehingga melalui internet bisa menarik tamu yang akan menginap. keputusan menginap di Aston Braga Hotel and Residence Bandung yang terdiri dari enam sub variabel yaitu pemilihan produk, pemilihan merek, pemilihan saluran, waktu menginap, jumlah pemesanan kamar, metode pembayaran. Dimensi yang mendapatkan nilai tertinggi ialah waktu menginap hal ini dikarenakan Aston Braga Hotel and Residence menawarkan variasi produk dan jasa pada saat tamu akan menginap, sehingga tamu akan mengalami kepuasan tersendiri. Pengaruh media advertising above the line terhadap 
keputusan menginap menunjukan nilai yang signifikan. Artinya media advertising above the line yang terdiri dari televisi, internet, magazine, billboard memberikan pengaruh yang cukup kuat terhadap keputusan menginap.

\section{DAFTAR PUSTAKA}

Ali Hasan. 2009. Edisi Baru Marketing. Jakarta. Pt Buku Kita.

Buchari Alma, 2011, Manajemen Pemasaran dan Pemasaran Jasa, Bandung:

Alfabeta

Pemasaran dan Pemasaran Jasa.
Bandung:
Alfabeta

Berkowitz. 2000. Marketing. Boston: Mc. Graw Hill

Clow Kenneth E \& Baack, Donald. 2012. Integrated Adcertising, Promotion and Marketing Communication.Fifth Edition. Global Edition

Pearson Education International.

Cronin, J. Joseph dan Gavin L.Fox. 2010. The Implications Of Advertising, Vol 39, no.2 (Summer 2010)

Damanik, Janianton, dan Weber, Helmar. F. 2006. Perencanaan Ekowisata: Dari Teori ke Aplikasi. Yogyakarta. Andi

Diah, Wardhani, Media Relations. Sarana Membangun Reputasi Organisasi, Graha Ilmu, Yogyakarta, 2008

Fandy Tjiptono. 2008. Strategi Pemasaran. Yogyakarta. Andi Offset.

Freddy Rangkuti. 2009. The Power Of Brands. PT Gramedia Pustaka Utama Jakarta

Griffin, RW, and Ronald J. Elbert. 2008. Business $\boldsymbol{8}^{\text {th }}$ Edition. New Jersey : Prentice Hall

Husain Umar. 2008. Metode Riset Bisnis. Jakarta. PT Gramedia Pustaka Utama

Hasto-Suprayogo. 2005. CorelDRAW untuk Bisnis. Jakarta: Pt. Elex Media Komputindo .

Hollensen. Svend.2003. Marketing Management A Relationship Approach. PrenticeHall. Pearson Education Limited, England.

Jhon Burnett dan Mariarty Sandra. 2011. Introduction to Marketing Communication, New Jersey:Prentice Hall

Kotler, Philip dan Amstrong. 2012. Priciple Marketing. Jakarta. Erlangga

Kotler, Philip, dan Kevin Keller. 2012. Marketing Management Edisi 13Jilid 2.
Jakarta.Erlangga.

Marpaung. 2002. Pengantar Pariwisata. Bandung. Alfabeta.

Nailatie Ma'Arif, Nelly. 2008. The Power Of Marketing. Jakarta: Selemba Empat.

Romi, Fjar Purnama. 2008. Pengaruh Keputusan Pembelian Kopi Bubuk Instan Torabika(survey pada Konsumen Kopi di Desa Sukamenak Kecamatan Margahayu Kabupaten Bandung), Skrip Pendidikan Manajemen Bisnis. Universitas Pendidikan Indonesia.

Silvia, David. 2009. Jurnal Of Marketing Management: HOD media Relations. Bandung. PT. Remaja Rosdakarya.

Shimp Therence A. 2010. Advertising Promotion and Other Aspects Of Integrated Marketing Communication $\boldsymbol{8 t}^{\boldsymbol{h}}$ Edition. Canada: Nelson Education

Sugiyono. 2010. Statistika Untuk Penelitian.Bandung: Alfabeta.

Suharmi, Arikunto. 2009. Prosedur Penelitian suatu pendekatan praktik. Jakarta. Rhineka Cipta.

Uma, Sekaran. 2006. Metodelagi Penetian Untuk Bisnis. Jakarta: Indeks

Widyatama, Rendra. 2007. Pengantar Periklanan. Yogyakarta : Pustaka Book Publisher

Yan Liou. Dian. 2010. Journal Of Vacation Marketing: Beyond Tokyo Rainbow Bridge Destination Image Portayed In Japanese Drama. 